\title{
CINÉTICA DE LA FERMENTACIÓN EN LA PRODUCCIÓN DE SUERO COSTEÑo
}

\section{FERMENTATION KINETICS FOR THE PRODUCTION OF SUERO COSTEÑO}

\author{
Diofanor Acevedo ${ }^{1}$, Luis Guzmán ${ }^{2}$, Aida Rodríguez ${ }^{3}$
}

\begin{abstract}
${ }^{1}$ Ingeniero de Alimentos, Ph.D. Ingeniería de Alimentos, Universidad de Cartagena, Cartagena-Colombia, e-mail: diofanor3000@gmail.com; ${ }^{2}$ Ingeniero de Alimentos, Especialista en Ingeniería Sanitaria y Ambiental, Universidad de Cartagena, Cartagena-Colombia; e-mail: lguzman1@unicartagena.edu.co; ${ }^{3}$ Ingeniera Química, Ph.D. Ingeniería de Alimentos, Universidad del Valle, Cali-Colombia, e-mail: aidarodriguezs@gmail.com
\end{abstract}

Rev. U.D.C.A Act. \& Div. Cient. 16(2): 427-433, Julio-Diciembre, 2013

\section{RESUMEN}

El Suero Costeño es un producto lácteo fermentado, que se obtiene por fermentación de la leche cruda. El objetivo de esta investigación fue establecer la proporción adecuada de cepas de Lactococcus lactis y Lactobacillus paracasei, teniendo en cuenta los parámetros de $\mathrm{pH}$, viabilidad y concentración de lactosa y ácido láctico. Para esto, se procedió a la preparación del cultivo iniciador, los pasos de selección, activación y ensayo de antagonismo de las cepas. Se trabajó con cepas de bacterias ácido lácticas, L. lactis ssp. lactis (ATCC29146) y L. paracasei ssp. paracasei (ATCC 334). Se realizaron ensayos de antagonismo in vitro y se implementaron pruebas de cinética de fermentación y viabilidad al producto final. Al aumentar la proporción de L. lactis en la relación $L$. paracasei a $L$. lactis, se observó un descenso rápido del $\mathrm{pH}$, reducción de sinéresis, rápido punto de gelificación y aumenta la viabilidad de los microorganismos.

Palabras clave: Cultivo iniciador, Lactococcus lactis, Lactobacillus paracasei, cinética de la fermentación, reducción de sinéresis.

\section{SUMMARY}

Suero costeño is a fermented milk product, obtained by fermentation of raw milk. The objective of this study was to establish the proper ratio of strains of Lactococcus lactis and Lactobacillus paracasei, taking into account the parameters of $\mathrm{pH}$, concentration and viability of lactic acid and lactose. For this the starter culture was prepared, taking into consideration the steps of selection, activation and antagonism assay strains. We worked with strains of lactic acid bacteria, L. lactis ssp. lactis (ATCC29146), L. paracasei ssp. paracasei (ATCC 334). Antagonism assays were performed in vitro. Moreover kinetics tests and viability of fermentation to the end product were implemented. By increasing the relationship of $L$. lactis to $L$. paracasei lactis, a rapid decrease in $\mathrm{pH}$, reduction of syneresis, gelation point and rapid improvement in the viability of the microorganisms was detected.

Key words: Starter culture, Lactococcus lactis, Lactobacillus paracasei, fermentation kinetics, reduced syneresis.

\section{INTRODUCCIÓN}

El Suero Costeño es un producto lácteo fermentado, elaborado tradicionalmente en la Costa Caribe colombiana, especialmente, en la mayoría de los municipios de los departamentos de Bolívar, Sucre, Córdoba y Cesar. También, se elabora en algunos municipios de los departamentos de Santander y Norte de Santander, debido a la influencia que tienen de la Costa Norte (Granados et al. 2012; Acevedo et al. 2010; Simancas et al. 2010). El producto final es similar a la crema agria, un poco ácida y generalmente es usado como aderezo, acompañando casi todas las comidas (Granados et al. 2012; Acevedo et al. 2010). Aunque se produce industrialmente, presenta un bajo consumo, debido a la diferencia detectada por los consumidores en el sabor y a la presencia de sinéresis. Estos problemas de calidad se han tratado de resolver, mediante el aumento del tiempo de fermentación y la adición de espesantes, lo cual, incrementa los costos y hace más perecedero el producto (Granados et al. 2012; Acevedo et al. 2010).

El uso de cultivos iniciadores en la elaboración de productos lácteos se generalizó, debido a la introducción de la pasteurización (Simancas et al. 2010; Cueto et al. 2007). Éstos, se definen como preparaciones que contienen microorga- 
nismos vivos, que son aplicados con el objeto de hacer uso de su metabolismo (Rashid et al. 2007; Chammas et al. 2006; Aichinger \& Servais, 2003). Las bacterias ácido lácticas (BAL) aisladas son las más usadas para el desarrollo de los cultivos iniciadores (Ayala \& Hernández, 2009). Dentro de estas están: Lactococcus lactis, Lactobacillus paracasei, Lactobacillus brevis, Enterococcus faecium (Simancas et al. 2010; Chammas et al. 2006; Patrignani \& Lanciotti, 2006).

La creciente demanda del yogur con textura mejorada, hace que la producción in situ de exopolisacáridos (EPS), por diferentes cultivos iniciadores, sea una alternativa viable, contribuyendo considerablemente a las propiedades organolépticas y de textura de éste (Prasanna et al. 2013).

Además, los EPS de diferentes especies de bacterias acidolácticas ( $\mathrm{LAB}$ ), se utilizan en el yogur, para evitar la sinéresis y reemplazar estabilizantes utilizados comercialmente (Prasanna et al. 2012). Los Streptococcus, Lactobacillus y Lactococcus son algunas de las géneros productores de EPS más utilizadas para producir yogur, con propiedades de textura mejoradas (Prasanna et al. 2013; 2012).

Hassan et al. (1995) descubrieron que el Lactococcus es un género constituido por la mayoría de los microorganismos mesófilos utilizados en la fermentación láctica y de las especies que integran este género y L. lactis es el más utilizado como cultivo iniciador.

En general, cuando se emplean inóculos aislados de productos artesanales para fermentar leche pasteurizada, el sabor y la textura no son significativamente diferentes al obtenido con el proceso artesanal y, adicionalmente, aumenta el rendimiento con la tecnificación del proceso (Alvarado et al. 2007; Patrignani \& Lanciotti, 2006; Castillo \& Lucey, 2005).

El defecto más común que presentan los productos lácteos gelificados y que afecta directamente su calidad organoléptica, es la sinéresis o goteo por separación del lactosuero de la cuajada. Esta se produce, debido al reajuste de la estructura interna de la matriz gelificada (Granados et al. 2012; Acevedo et al. 2010) y, en ella, se observa líquido en la superficie de los productos lácteos, causando el rechazo por el consumidor. La adición de solutos, como las proteínas del lactosuero y la leche en polvo, con el propósito de elevar los sólidos totales, han sido hasta ahora las técnicas más usadas, para reducir este inconveniente (Granados et al. 2012). Otro mecanismo muy usado es la homogenización (Amatayakul et al. 2006; Aichinger \& Servais, 2003).

Con el aislamiento de los microorganismos involucrados en la fermentación de la leche para la producción de suero costeño, se puede obtener un fermento de mayor eficiencia, libre de contaminantes, de características definidas, que permite determinar las condiciones más adecuadas de fermentación, para lograr un producto de mejor calidad higiénica, sensorial, nutricional y microbiológica, de menor tiempo de elaboración, con un mayor período de vida útil (Simancas et al. 2010; Cueto et al. 2007) y con una reducción de la sinéresis, debido a la producción de EPS, que ayudan a estabilizar la red de caseína y le proporcionan mayor resistencia al producto (Wacher-Rodarte et al. 1993).

El objetivo del presente trabajo fue establecer la proporción adecuada de cepas de L. lactis y L. paracasei, para la producción de suero costeño, teniendo en cuenta los parámetros de $\mathrm{pH}$, viabilidad y concentración de lactosa y ácido láctico.

\section{MATERIALES Y MÉTODOS}

En la preparación del cultivo láctico iniciador, se tuvieron en cuenta los pasos de selección, de activación y de ensayo de antagonismo de las cepas. Se trabajó con cepas de colección de bacterias ácido lácticas, L. lactis ssp. lactis (ATCC29146) y L. paracasei ssp. paracasei, (ATCC 334). Esta selección, se realizó a partir de los resultados obtenidos en trabajos previos de aislamiento y selección de cepas, realizados en el Suero Costeño, producido artesanalmente (Cueto et al. 2007; Kristo \& Biliaderis, 2003).

Las cepas del cultivo puro crio-conservado se activaron, transfiriendo $1 \mathrm{~mL}$ del cultivo a un tubo de ensayo, que contenía $9 \mathrm{~mL}$ del medio de cultivo MRS, especial para bacterias lácticas. El tubo de ensayo inoculado, se incubó durante 24 horas, a $30^{\circ} \mathrm{C}$. Pasado el tiempo de incubación, se sembró en superficie cada una de las bacterias en cajas Petri, con AgarMRS modificado, con azul de anilina (medio en que las colonias de bacterias lácticas presentan un característico color azul) y se incubó durante 48 horas, a $30^{\circ} \mathrm{C}$. A continuación, se verificó la pureza con tinción de Gram y se observaron las características morfológicas al microscopio (Patrignani \& Lanciotti, 2006). Se tomó una colonia de cada tubo de ensayo con MRS y se transfirieron a tubos que contenían $9 \mathrm{~mL}$ de leche. Posteriormente, se incubó cada cepa a $30^{\circ} \mathrm{C}$, por 24 horas. Se estableció que todos los cultivos tuvieran una concentración de $10^{8} \mathrm{UFC} / \mathrm{mL}$ (Simancas et al. 2010).

Ensayo de antagonismo in vitro: Se realizó una siembra en profundidad en caja petri por separado de L. lactis (ATCC29146), L. paracasei (ATCC 334) en medio MRS, actuando la primera como la bacteria indicadora y, luego, la segunda, se dejó incubar durante 48 horas. A continuación, se tomaron trozos de $7 \mathrm{~mm}$ de diámetro del cultivo láctico y de un testigo de MRS sin bacterias, utilizando un sacabocados y se depositaron sobre la siembra de la cepa indicadora, 
se incubaron a $35^{\circ} \mathrm{C}$, durante 24 horas, en un ambiente microaerofílico, para permitir el crecimiento de ambas cepas. Los diámetros de los halos fueron reportados, incluyendo los $7 \mathrm{~mm}$ de diámetro de los discos, con las bacterias lácticas sembradas en profundidad (Alvarado et al. 2007; Ayala \& Hernández, 2009).

Preparación del suero costeño: Se mezcló la leche en polvo con agua destilada y se agitó hasta disolver completamente y alcanzar $12 \%$ de sólidos totales. Después, se calentó a $80^{\circ} \mathrm{C}$, por 20 minutos. Posteriormente, $300 \mathrm{~mL}$ de leche se inocularon a $30^{\circ} \mathrm{C}$, con el $10 \% \mathrm{v} / \mathrm{v}$, de cada una de las combinaciones de las cepas L. lactis ssp. lactis (ATCC29146) y L. paracasei ssp. paracasei (ATCC 334), en las proporciones 30:70, 40:60, 50:50, 60:40, 70:30 y 80:20, respectivamente.

Los volúmenes de la adición se variaron dependiendo de la proporción, a la cual, se deseaban adicionar los microorganismos en la leche; la suma de los dos volúmenes fue del $10 \% \mathrm{v} / \mathrm{v}$ del volumen total de la leche. Se incubó a la temperatura de fermentación de $30^{\circ} \mathrm{C}$, por 16 horas; luego de obtenido el coágulo, se realizó la ruptura y la separación del $30 \%$ del lactosuero, en relación al volumen inicial de leche, haciendo pasar por un filtro; se adicionó 1,2\% de sal ( $\mathrm{NaCl}$ ), por cada litro de leche y se homogenizó, para conseguir una consistencia adecuada y se calculó el rendimiento (Saarela et al. 2000).

Cinética de la fermentación: Se determinaron el pH, con el uso de un potenciómetro y la lactosa, de acuerdo a Nelson (1944), aplicando un método fotométrico con reactivos de cobre y de arsenomolibdato. La densidad óptica del color desarrollado es proporcional a la lactosa tomada y es estable durante largos períodos de tiempo. Para la vialidad, se utilizó la técnica de recuento estándar en placa en superficie, sobre MRS y se determinó ácido láctico empleando la técnica de Gil-Horán et al. (2008), por medio de cromatografía líquida de alta presión CLAR (HPLC, en inglés).

Determinación de sinéresis: Después de dos días de almacenamiento, refrigerado a $5^{\circ} \mathrm{C}$, se agitaron los sueros costeños por 2 minutos, a 400rpm, con un agitador magnético y, posteriormente, fueron centrifugados a $5000 \mathrm{xg}$, a $20^{\circ} \mathrm{C}$. La sinéresis, se calculó como la cantidad de líquido que se separa del suero costeño, debido a la centrifugación con relación a la masa total que fue centrifugada.

El análisis estadístico de los datos y la obtención del diseño central compuesto rotable, se realizó con el programa MINITAB 14, mediante pruebas de varianza (ANOVA), manteniendo un intervalo de confianza del $95 \%$.

\section{RESULTADOS Y DISCUSIÓN}

Antagonismo in vitro: La bacteria L. lactis mostró tener una débil inhibición sobre la $L$. paracasei, ya que los halos fueron menores de $0,3 \mathrm{~cm}$, mientras que la $L$. paracasei no presentó ninguna inhibición sobre la L. lactis.

Cinética de la fermentación: Como se observa en la figura 1, todas las combinaciones de cepas alcanzaron el $\mathrm{pH}$ de 4,6, punto isoeléctrico de las caseínas, entre las 8 y 12 horas; las combinaciones de cepas 30:70 y 40:60 L. paracasei : L. lactis alcanzaron el punto isoeléctrico más rápido (8 ho-

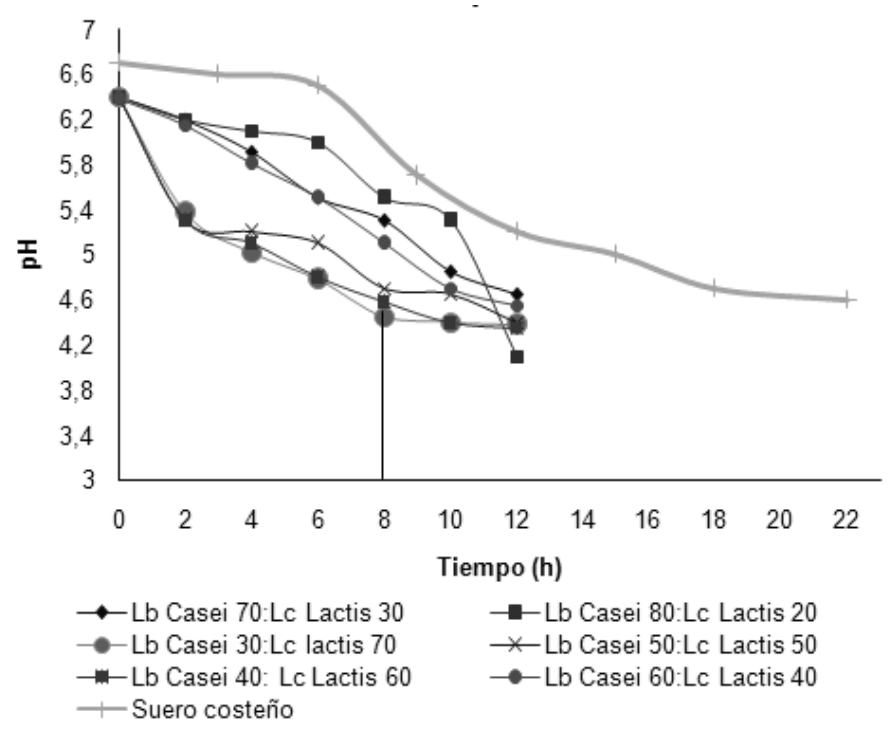

Figura 1. Evolución del pH a diferentes proporciones de Lactococcus lactis y Lactobacillus paracasei. 
ras). Esta velocidad de acidificación es más rápida que la que presenta el producto artesanal (24 horas) y la reportada por Simancas et al. (2010), la cual, es de 12 horas. Al aumentar la proporción de $L$. lactis el $\mathrm{pH}$ desciende más rápidamente, resultados que coinciden con Cueto et al. (2007), para quienes $L$. lactis ssp lactis es la principal causa de acidificación en los quesos artesanales y L. paracasei causa proteólisis y lipólisis, contribuyendo al flavor característico. Caridi et al. (2003) consideraron adecuadas, para su inclusión en cultivos iniciadores, aquellas cepas de L. lactis ssp. Lactis, que disminuyeron el $\mathrm{pH}$ a valores inferiores a 5 , después de 24 horas de incubación, a $30^{\circ} \mathrm{C}$. Como las combinaciones de cepas 50:50, 30:70 y 40:60 de L. paracasei : L. lactis presentaron los mejores resultados; las siguientes pruebas de la cinética de fermentación, se les realizaron solamente a estas combinaciones.
La lactosa es el mayor azúcar fermentable de la leche y es metabolizado por las LAB, para obtener energía (Saarela et al. 2000). La concentración inicial de lactosa fue de 4,7\%, como se observa en la figura 2; la concentración de lactosa disminuye significativamente de siete a ocho horas, para las combinaciones de cepas 30:70 y 40:60 y esto coincide con el aumento significativo de la concentración de ácido láctico (Figura 3) y la viabilidad (Figura 4), mientras que para la combinación 50:50, la velocidad de disminución de la concentración de lactosa es baja, igual que el aumento de la concentración de ácido láctico y de la viabilidad, estos resultados están de acuerdo con los de Patrignani \& Lanciotti (2006), quienes estudiaron la utilización de varios cultivos iniciadores, para la producción de Maasai, un producto lácteo fermentado de leche cruda.

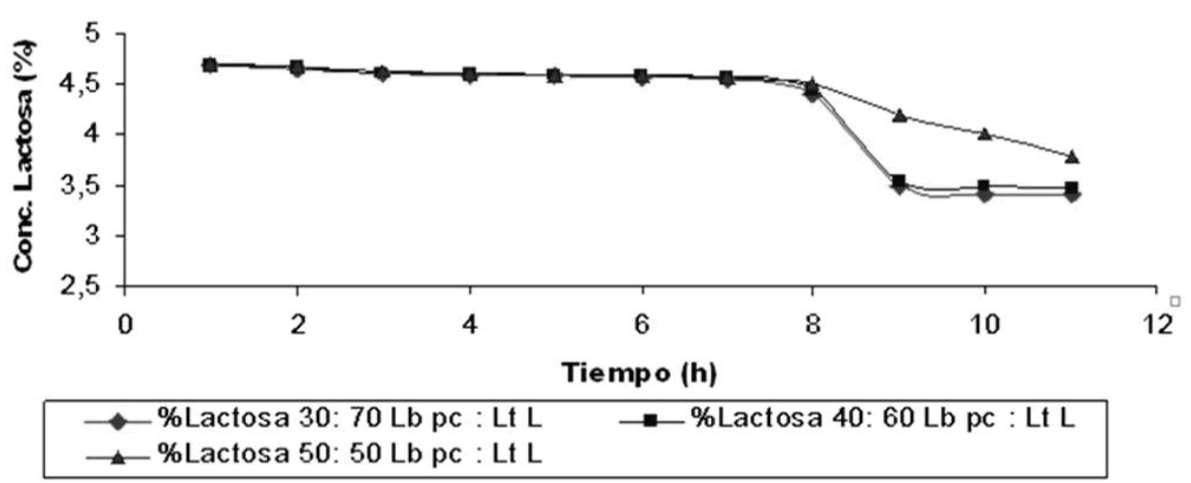

Figura 2. Evolución en la concentración de lactosa en la fermentación del suero costeño a las proporciones de 70:30, 40:60 y 50:50 de Lactococcus lactis y Lactobacillus paracasei.

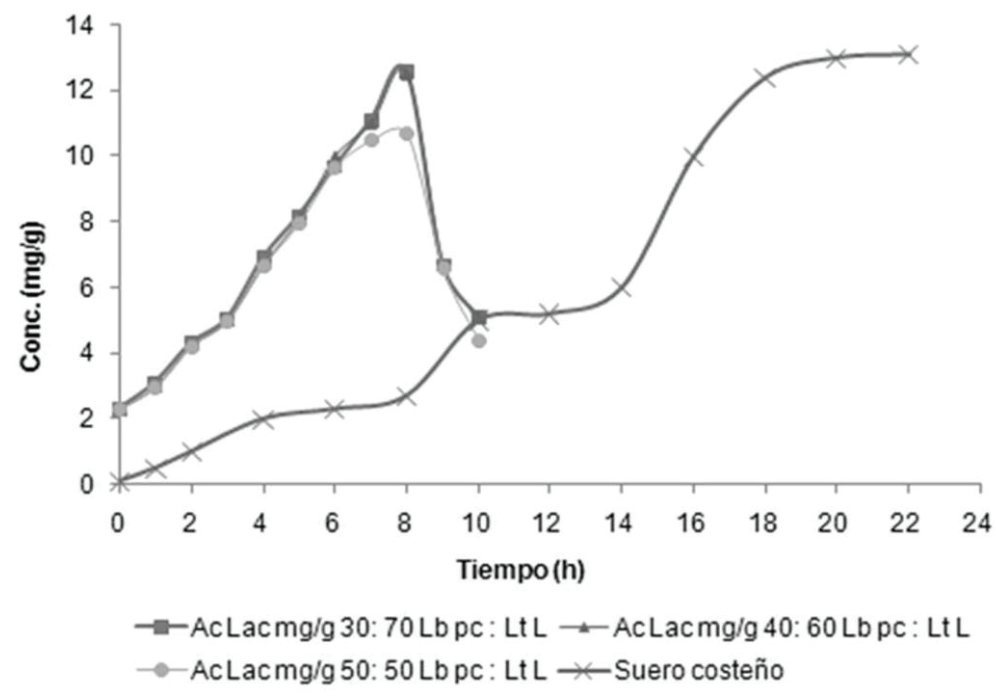

Figura 3. Evolución en la concentración de ácido láctico en la fermentación del suero costeño a las proporciones de 70:30, 40:60 y 50:50 de Lactococcus lactis y Lactobacillus paracasei. 


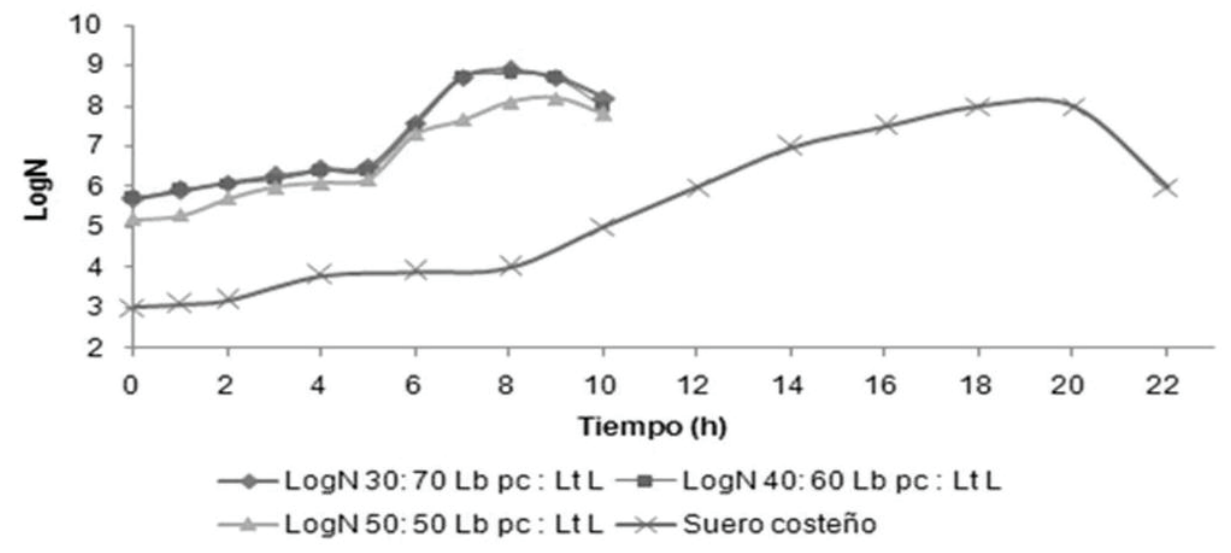

Figura 4. Viabilidad de las combinaciones de Lactococcus lactis y Lactobacillus paracasei.

Pruebas realizadas al producto final: Todas las combinaciones de cepas presentan número de células viables por encima de 7 log UFC/g (Tabla 1), con lo cual, cumplen con la norma internacional que establece que debe estar por encima de $6 \log$ UFC/g, al momento de consumirse el producto, para que las bacterias probióticas ejerzan sus efectos benéficos, sobre la salud (Simancas et al. 2010; Samona \& Robinson, 1991). Las combinaciones de cepas 30:70 y 40:60 L. paracasei : L. lactis presentan viabilidad mayor de $8 \mathrm{log}$ UFC/g, a los 60 días de almacenamiento refrigerado; estos resultados están de acuerdo con los obtenidos por Patrignani \& Lanciotti, (2006), para Maasai, una leche tradicional de Kenia meridional y Tanzania septentrional.

La mayor viabilidad se presenta en las combinaciones, donde las proporciones de L. lactis es más alta, lo que puede ser debido a que éste se adapte mejor a las condiciones de temperatura, $\mathrm{pH}$ y a la composición de la leche, tal como indican Acevedo et al. (2010), en su trabajo, donde concluyeron que estas variantes del proceso afectan significativamente la viabilidad de las LAB.
Los resultados consignados en la tabla 2 muestran que la sinéresis del suero costeño disminuye y el rendimiento se incrementa en la medida que se aumenta la proporción de L. lactis. Esto puede ser debido, según los hallazgos de otros estudios con yogures elaborados con LAB productores de EPS, a la producción de EPS, que ayudan a estabilizar la red de caseína, le proporcionan mayor resistencia, mejoran las propiedades reológicas incluyendo la reducción de sinéresis (Prasanna et al. 2013; 2012).

De los resultados se puede concluir que al aumentar la proporción de $L$. lactis en la relación $L$. paracasei : L. lactis, la lactosa se transforma más rápidamente en ácido láctico, el $\mathrm{pH}$ de coagulación se alcanza en menor tiempo, la sinéresis se reduce. Las mejores proporciones de $L$. paracasei : $L$. lactis fueron 30:70 y 40:60.

Conflicto de intereses: El manuscrito fue preparado y revisado con la participación de todos los autores, quienes declaramos que no existe ningún conflicto de intereses, que ponga en riesgo la validez de los resultados presentados.

Tabla 1. Viabilidad de las combinaciones de cepas en el suero costeño, a $4^{\circ} \mathrm{C}$. $\log$ UFC/g.

\begin{tabular}{|c|c|c|c|c|c|}
\hline Cepas & \multicolumn{5}{|c|}{ Tiempo } \\
\hline L. paracasei : L. lactis & 0 días & 20 días & 30 días & 50 días & 60 días \\
\hline 7030 & 9,6 & 9,3 & 8,6 & 8,2 & 7,2 \\
\hline 8020 & 9,5 & 9,1 & 8,2 & 7,1 & 7,2 \\
\hline 3070 & 9,7 & 9,6 & 9,7 & 8,3 & 8,1 \\
\hline 5050 & 9,6 & 9,3 & 8,8 & 8,2 & 7,4 \\
\hline 4060 & 9,8 & 9,7 & 9,2 & 8,4 & 8,4 \\
\hline 6040 & 9,7 & 9,5 & 9,1 & 8,2 & 7,6 \\
\hline
\end{tabular}


Tabla 2. Sinéresis y rendimiento del suero costeño a diferentes proporciones de Lactococcus lactis y Lactobacillus paracasei.

\begin{tabular}{|c|c|c|}
\hline L. paracasei $:$ L. lactis & Sinéresis & Rendimiento \\
\hline $\mathbf{3 0 : 7 0}$ & 16 & 49,1 \\
\hline $\mathbf{4 0 : 6 0}$ & 16 & 49,2 \\
\hline $\mathbf{5 0 : 5 0}$ & 21 & 45,0 \\
\hline $\mathbf{6 0 : 4 0}$ & 23 & 45,0 \\
\hline $\mathbf{7 0 : 3 0}$ & 26 & 45,0 \\
\hline $\mathbf{8 0 : 2 0}$ & 28 & 45,0 \\
\hline $\begin{array}{c}\text { Suero } \\
\text { Industrial }\end{array}$ & 27 & 43,0 \\
\hline
\end{tabular}

\section{BIBLIOGRAFÍA}

1. ACEVEDO, D.; RODRÍGUEZ, A.; FERNÁNDEZ, A. 2010. Efecto de las variables de proceso sobre la cinética de acidificación, la viabilidad y la sinéresis del suero costeño colombiano. Inf. Tecn. (Chile). 21(2):29-36.

2. AICHINGER, P.; SERVAIS, C. 2003. Fermentation of a skim milk concentrate with Streptococcus thermophilus and chymosin: structure, viscoelasticity and syneresis of gels. Colloid Surfaces. (United States). 31:243-255.

3. ALVARADO, C.; CHACÓN, Z.; OTONIEL, J.; GUERRERO, B.; LÓPEZ, G. 2007. Aislamiento, identificación y caracterización de bacterias acido lácticas de un queso venezolano ahumado andino artesanal su uso como cultivo iniciador. Rev. Cient. (México). 17(3):301-308.

4. AMATAYAKUL, T.; SHERKAT, F.; SHAH, N. 2006. Physical characteristics of set yoghurt made with altered with altered casein to whey protein ratios and EPS producing starter cultures at 9 and $14 \%$ total solids. Food Hydrocoll. (United States). 20(2-3):314-324.

5. AYALA, I.; HERNÁNDEZ, H. 2009. Effect of protein supplementation on the rheological characteristics of milk permeates fermented with exopolysaccharide-producing Lactococcus lactis subsp. cremoris. Food Hydrocoll. 23(5):1299-1304.

6. CARIDI, P.; MICARI, P.; CAPARRA, P.; CUIFARI, A.; SARULLO, V. 2003. Ripening and seasonal changes in microbial groups and in physico-chemical properties of the ewes' cheese Pecorino del Poro. Int. Dairy J. (United States). 13(2-3):191-200.
7. CASTILLO, M.; LUCEY, J. 2005. Effect of temperature and inoculum concentration on gel microstructure, permeability and syneresis kinetics Cottage cheesetype gels. Int. Dairy J. 16(2-3):153-163.

8. CHAMMAS, G.; SALIBA, R.; CORRIEU, G.; BÉAL C. 2006. Characterisation of lactic acid bacteria isolated from fermented milk "laban". Int. J. Food Microbiol. (United States). 110(1):52-61.

9. CUETO, C.; GARCÍA, D.; GARCÉS, F.; CRUZ, J. 2007. Preliminary studies on the microbiological characterization of lactic acid bacteria in suero costeño, a Colombian traditional fermented milk product. Rev. Latinoam. Microbiol. (Mexico). 49(1-2):12-18.

10. GIL-HORÁN, R.; DOMÍNGUEZ-ESPINOSA, R.M.; PACHO-CARRILLO, J. 2008. Bioproducción de ácido láctico a partir de residuos de cáscara de naranja: Procesos de separación y purificación. Tecn., Cienc., Edu. (México). 23(2):79-90.

11. GRANADOS, C.; ACEVEDO, D.; TORRES, R. 2012. Calidad de la leche y del suero costeño de los municipios Turbaco, Arjona y Carmen de Bolívar-Colombia. Rev. Lasallista de Investigación. (Colombia). 9(2):132137.

12. HASSAN, A.; FRANK, J.; FARMER, M.; SCHMIDT, K.; SHALABI, S. 1995. Formation of yogurt microstructure and three-dimensional visualization as determined by confocal scanning laser microscopy. J. Dairy Sci. (United States). 78(12):2629-2636.

13. KRISTO, E.; BILIADERIS, C. 2003. Modelling of rheological, microbiological and acidification properties of fermented milk product containing a probiotic strain 
of Lactobacillus paracasei. Int. Dairy J. 13(7):517528.

14. NELSON, N. 1944. A photometric adaptation of Somogyi method for the determination of glucose. J. Biol. Chem. (United States). 153:375-380.

15. PATRIGNANI, F.; LANCIOTTI, R. 2006. Potencial of functional strains, isolated from traditional Maasai milk, as starters for the production of fermented milks. Int. J. Food Microbiol. (United States). 107(1):111.

16. PRASANNA, P.; GRANDISON, A.; CHARALAMPOPOULOS, D. 2013. Microbiological, chemical and rheological properties of low fat set yoghurt produced with exopolysaccharide (EPS) producing Bifidobacterium strains. Food Res. Int. (United States). 51(1):15-22.

17. PRASANNA, P.; BELL, A.; GRANDISON, A.; CHARALAMPOPOULOS, D. 2012. Emulsifying, rheological and physicochemical properties of exopolysaccharide produced by Bifidobacterium longum subsp. infantis CCUG 52486 and Bifidobacterium infantis NCIMB 702205. Carbohydr. Polym. (United States). 90(1):533-540.

18. RASHID, M.; TOGO, K.; MIYAMOTO, T. 2007. Identification and characterization of dominant lactic acid bacteria isolated from traditional fermented milk Dahi in Bangladesh. World J Microbiol Biotechnol. (United States). 23(1):125-133.

19. SAARELA, M.; MOGENSEN, G.; FONDEN, R.; MATTO, J. 2000. Probiotic bacteria: Safety, funcional and technological properties. J. Biotechn. Finland. 84(3):197-215.

20. SAMONA, A.; ROBINSON, R. 1991. Enumeration of bifidobacteria in dairy products. J. Soc. Dairy Techn. (United States). 44(3):64-66.

21. SIMANCAS, M.; ARTEAGA, M.; PÉREZ, Y.; SOTO, M.; SALCEDO, J. 2010. Characterization and study of spontaneous fermentation of fermented milk product (Suero costeño) produced in Monteria. Rev. MVZ Córdoba. 15(1):1944-1953.

22. WACHER-RODARTE, C.; GALVAN, M.; FARRES, A.; GALLARDO, F.; MARSHALL, V.; GARCIA, M. 1993. Yogurt production from reconstituted skim milk powders using different polymer and non-polymerforming starter cultures. J. Dairy Res. 60(2):247-254.

Recibido: Febrero 27 de 2013

Aceptado: Octubre 10 de 2013

Como citar:

Acevedo, D.; Guzmán, L.; Rodríguez, A. 2013. Cinética de la fermentación en la producción de suero costeño. Rev. U.D.C.A Act. \& Div. Cient. 16(2): 427-433. 